\title{
REDUÇÃO NA CONTAMINAÇÃO SUPERFICIAL DE CARCAÇAS SUÍNAS: UM PROCESSO ALTERNATIVO
}

\author{
Marcia Pivotto ${ }^{1}$, Ana Paula Dutra Resem Brizio ${ }^{2}$, Luis César de Castro ${ }^{3}$
}

\footnotetext{
${ }^{1}$ Especialista em Tecnologia de Alimentos, Centro Universitário Univates, RS. E-mail: pivottomarcia@yahoo.com.br

${ }^{2}$ Universidade Federal do Rio Grande, FURG, RS. E-mail: anabrizio@yahoo.com.br

${ }^{3}$ Centro Universitário Univates, RS. E-mail: lucamsc@univates.br
}

\section{RESUMO}

Este estudo foi realizado para verificar o potencial de descontaminação bacteriano no emprego de um chamuscador (calor seco) como última etapa da área "suja" do abate de suínos. Foram coletadas amostras da superfície de carcaças após a passagem destas por dois diferentes tipos de procedimentos de abate: o tradicional denominado "controle", e o adaptado contemplando mais um chamuscador, chamado de "teste". As amostras coletadas foram analisadas mediante quantificação de micro-organismos mesófilos aeróbios estritos e facultativos. Os resultados microbiológicos encontrados apontaram uma redução de aproximadamente dois ciclos logarítmicos quando efetuado o abate denominado "teste" em comparação ao "controle", evidenciando que o uso de calor seco na última etapa da área "suja" do abate de suínos pode configurar-se como uma metodologia alternativa eficiente na redução da carga microbiana superficial de carcaças, consistindo em uma adaptação barata, simples e segura à rotina convencional de abate.

Palavras-chave: Calor seco, descontaminação,carcaça

\section{REDUCTION OF THE CONTAMINATION OF SWINE CARCASSES: AN ALTERNATIVE PROCESS}

\begin{abstract}
This study was conducted to verify the potential for bacterial decontamination by using a scorcher (dry heat)as the last step of the "dirty" area of the swine slaughter. Swabs were collected at the carcasses surface after the passage in two different types of slaughter procedures: the traditional, called "control", and the adapted, consisting of another scorcher, called" test". The samples were analyzed by quantification of strict and facultative aerobic mesophilic




\section{REDUÇÃO NA CONTAMINAÇÃO SUPERFICIAL DE CARCAÇAS SUÍNAS: UM PROCESSO \\ ALTERNATIVO}

microorganisms, strict and facultative, through the traditional method of cultivation. The microbiological results indicated reduction of about two log cycles when the slaughter called "test" was performed, in comparison to "control". This shows that the use of dry heat at the final stage of the "dirty" area of the swine slaughter may be adopted as an alternative effective methodology in reducing the microbial load of the carcasses surface, consisting in a cheap, simple and safe adaptation to the conventional slaughter.

Keywords: Dry heat, decontamination, carcasses

INTRODUÇÃO

A possibilidade de ocorrer contaminação microbiana de carcaças de suínos em abatedouros é ampla (LIMA et al., 2004 e CATTANI et al., 2013). A presença de micro-organismos é resultante da contaminação dos animais vivos, dos equipamentos, dos manipuladores e do ambiente de processamento (SOFOS \& GEORNARAS, 2010). A abordagem básica para reduzi-lacompreende o acompanhamento rigoroso do abate com o uso de boas práticas de fabricação (FAUCITANO et al., 2010). No entanto, mesmo com as melhores práticas sanitárias, as carcaças suínas aindapodemconter cargas microbianas que irão afetar negativamente a vida-útil de seus produtos derivados (COATES et al., 1995).

Nesse sentido, métodos de descontaminação bacteriana de superfície podem ser necessários como uma efetiva intervenção (SWANENBURG et al., 2001).
Os principais métodos de descontaminação são baseados na imersão, lavagem ou aspersão de soluções químicas e/ou aplicação de calor (úmido ou seco) na superfície da carcaça (HUFFMAN, 2002 e KOOHMARAIE et al., 2005), sendo bastante utilizados em países como EUA, Canadá e Austrália.

No Brasil e na Comunidade Européia apenas os métodos de descontaminação físicos de aplicação de calor seco são autorizados. Nestes países, se destaca o uso do chamuscamento ou flambagem, etapa onde as carcaças suínas passam pelo interior de um equipamento que possui bicos que lançam chamas sobre a sua superfície destruindo grande parte dos microorganismos localizados na pele do animal e queimando os resíduos de cerdas remanescentes (INTERNATIONAL COMMISSION ON MICROBIOLOGICAL SPECIFICATIONS FOR FOODS, 2005). $\mathrm{Na}$ legislação brasileira, a operação de chamuscamento é obrigatória, sendo seguida 
de toalete e posterior lavagem das carcaças com água a temperatura ambiente (chuveiro higiênico), etapas que caracterizam o encerramento das operações da zona "suja" do abate de suínos (BRASIL, 1995).

Estudos em diversos países têm sido realizados com o intuito de verificar a eficiência do uso de metodologias alternativas de descontaminação de carcaças mediante aplicação de substâncias químicas (CATTANI et al., 2013 e CARPENTER et al., 2011). No entanto, poucas pesquisas abordam o uso de novos procedimento sutilizando a descontaminação física através da aplicação de calor seco, metodologia autorizada no Brasil.Por isso, este trabalho busca avaliar o potencial de descontaminação bacteriano no emprego de um segundo chamuscador em lugar do chuveiro higiênico durante a última etapa da área "suja" do abate de suínos.

\section{MATERIAL E MÉTODOS}

Esta pesquisa foi desenvolvida em um abatedouro de suínos, sob Inspeção Federal, situado no estado do Rio Grande do Sul, com capacidade de abate de 3000 animais por dia.

\section{Características dos equipamentos} utilizados: O chuveiro higiênico dispunha de oito bicos aspersores com pressão de $3 \mathrm{kgf} / \mathrm{cm}^{2}$ utilizando água potável à temperatura ambiente. $\mathrm{O}$ chamuscador continha oito bicos com consumo de $3 \mathrm{~g}$ de gás liquefeito de petróleo por suíno, alcançando uma temperatura de aproximadamente $300^{\circ} \mathrm{C}$. Em ambos os equipamentos o tempo de permanência de cada carcaça foi de $2 \mathrm{~s}$.

As etapas de abate seguidas durante o estudo foram registradas (Figura 1). O fluxograma do processo normal de abate de suínos (controle), segue a legislação brasileira (BRASIL, 1995) (Figura 1A), enquanto a adaptação foi realizada com a substituição do $2^{\circ}$ Chuveiro Higiênico por mais um Chamuscador (teste) (Figura 1B).

Imediatamente após a passagem das carcaças pelas etapas de chuveiro higiênico e chamuscador foram coletados swabs em 30 carcaças para cada processo avaliado (controle - Figura 1Ae teste - Figura 1B). As amostras foram colhidas com emprego de esponja estéril embebida em água peptonada $0,1 \%$ acrescido de $0,85 \%$ de $\mathrm{NaCl}$. Em cada carcaça foi analisada uma área total de 400 $\mathrm{cm}^{2}$, seguindo metodologia do Ministério da Agricultura Pecuária e Abastecimento (BRASIL, 2007). Após a coleta, os swabs foram imediatamente enviados ao laboratório para realização das análises de detecção de micro-organismosmesófilos aeróbicos estritos e facultativos, seguindo 


\section{REDUÇÃO NA CONTAMINAÇÃO SUPERFICIAL DE CARCAÇAS SUÍNAS: UM PROCESSO ALTERNATIVO}

metodologia tradicional de cultivo da American Public Health Association (APHA, 2001). As análises microbiológicas foram realizadas em triplicata para cada carcaça e os resultados expressos em Unidade Formadoras de Colônia (UFC) $/ \mathrm{cm}^{2} /$ amostra. Os resultados das análises microbiológicas das amostras controle e teste foram submetidos à análise estatística de comparações de médias pelo Teste t, através do programa Statistica 7.0, com nível de significância de $5 \%(\mathrm{p}<0,05)$, para verificar a eficiência da utilização de dois chamuscadores no processo de abate de suínos.
A

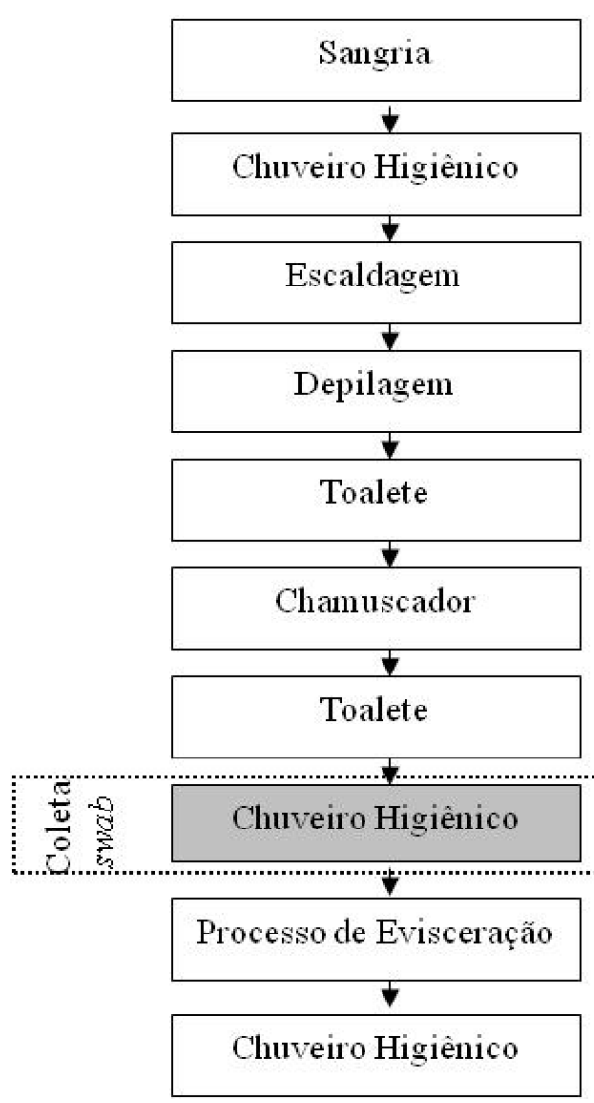

B

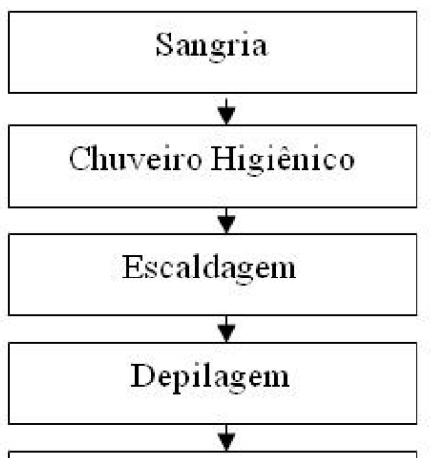

Toalete

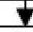

Chamuscador I

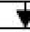

Toalete

Chamuscador II 衰敦

Processo de Evisceração

Chuveiro Higiênico

Figura 1. Fluxogramas de abate utilizados durante o estudo, com indicação da etapa onde foram coletadas amostras. (A) Fluxograma original da empresa avaliada (controle); (B) Fluxograma com adaptações, contemplando a substituição do segundo chuveiro higiênico por mais um chamuscador (teste). 


\section{RESULTADOS E DISCUSSÃO}

Os resultados das análises microbiológicas de todas as carcaças suínas avaliadas nas duas situações de abate estudadas (teste e controle) foram registrados (Figura 2).

As barras de erro representam o desvio padrão das triplicatas de cada medição. Os índices de contaminação observados (Figura 2) para a situação de abate "controle" corroboram com os estudos realizados por outros pesquisadores, como Bessa et al. (2004); Silva et al. (2009); Sofos \& Geornaras (2010) e Lara et al. (2011), que avaliaram a contaminação de carcaças suínas e demonstraram que mesmo com a utilização de boas práticas durante o processamento, a quantidade de micro-organismos encontrados indica para a importância em se manejar os riscos associados a segurança da carne, desenvolvendo estratégias de controle alternativos a legislação vigente (BRASIL, 1995) durante as etapas do abate de suínos.

Os resultados médios encontrados nas análises de quantificação de microorganismos mesófilos presentes na superfície das carcaças suínas avaliadas após a etapa de lavagem com chuveiro higiênico (processo controle - Figura 1A) e após o procedimento de abate contemplando mais um chamuscador (teste - Figura 1B) foram de
$2,2 \times 10^{4} \pm 0,33 \mathrm{UFC} / \mathrm{cm}^{2}$ e $3,0 \times 10^{2} \pm 0,22$ $\mathrm{UFC} / \mathrm{cm}^{2}$, respectivamente. A análise estatística das contagens microbiológicas evidenciou uma redução significativa $(\mathrm{p}<0,05)$ de aproximadamente dois ciclos logarítmicos quando efetuada a utilização do abate denominado "teste" em comparação ao "controle". Estes resultados mostram que a ação mecânica da água (chuveiro higiênico, pressão de $3 \mathrm{Kgf} / \mathrm{cm}^{2} / 2 \mathrm{~s}$ )sobre as carcaças foi menos eficiente na remoção física dos micro-organismos do que a atuação do calor (chamuscador, $300^{\circ} \mathrm{C}$ por $2 \mathrm{~s}$ ). Segundo Jay (2005) e Tortora et al. (2008), o calor é um dos mais importantes e eficientes métodos utilizados para o controle do crescimento e eliminação de micro-organismos. Sua ação na superfície de carcaças promove a desnaturação de proteínas estruturais e enzimas, levando a perda da integridade celular e, consequentemente, a morte dos organismos.

Reduções menos expressivas da carga bacteriana superficial de carcaças suínas foram constatadas em estudos que utilizaram métodos de descontaminação baseados no uso de ácidos orgânicos, de água quente sob a forma de vapor e/ou a associação do tratamento térmico com o químico. 


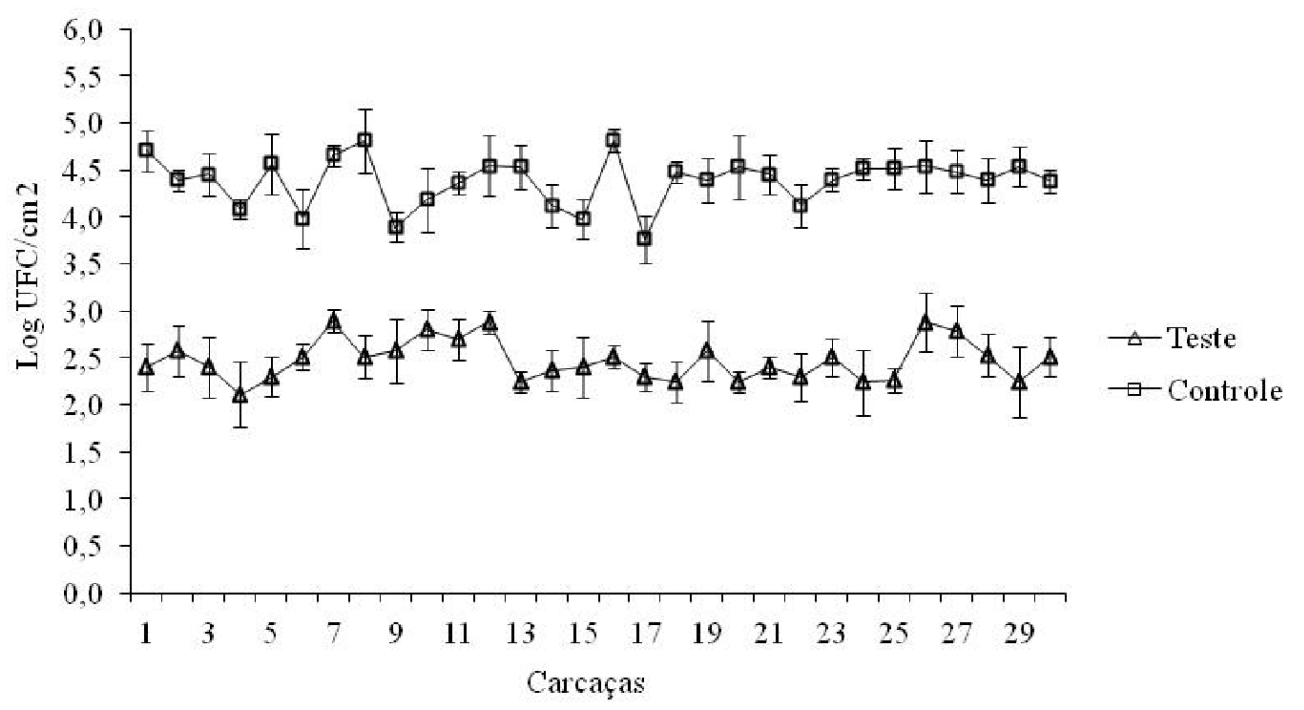

Figura 2. Resultados microbiológicos de superfície de carcaças suínas em dois processos distintos de abate (controle - contendo três chuveiros higiênicos e um chamuscador; e teste - com dois chuveiros higiênicos e dois chamuscadores).

De acordo com pesquisas realizadas pelo INTERNATIONAL COMMISSION ON MICROBIOLOGICAL SPECIFICATIONS FOR FOODS (2005), a aplicação de ácido lático (1\%) na superfície de carcaças bovinas e suínas reduziu a contagem de microorganismos mesofilos em $0,8 \log _{10}$. Segundo Passai et al. (1992); Carpenter et al. (2011) e Machado et al. (2013) comparando-se o antes e o depois da aplicação de diferentes tratamentos, a maior redução obtida foi de aproximadamente um ciclo logarítmico após a utilização sinestésica de vapor e soluções de ácidos orgânicos (acético e lático) na carne suína.

Durante a aplicação dos métodos de descontaminação, aspectos como tempo de exposição, concentração das substâncias e pressão dos bicos aspersores devem ser levados em conta, pois têm um substancial impacto na magnitude da redução microbiana (SOFOS \& SMITH, 1998; FAUCITANO, et al. 2010; MACHADO, et al. 2013). Nesse sentido, quando confrontado o tempo de exposição dos métodos alternativos de abate propostos por Passai et al. (1992); Carpenter et al. (2011) e Machado et al. (2013), de 6 a 35s, com os deste estudo, de $2 \mathrm{~s}$, constatam-se benefícios no uso do abate conforme sugerido na Figura 1B, cuja eliminação bacteriana foi superior em um tempo menor, tornando viável a sua implementação sem alterações significativas no tempo de processamento. 
Além disso, cabe salientar, que tratamentos com calor úmido (vapor)e/ou uso de ácidos orgânicos (em concentrações superiores a $2 \%$ ) podem promover alterações de cor, odor, sabor, consistência, declínios de $\mathrm{pH}$ e aumento do teor de umidade do músculo suíno (FORSYTHE, 2002; SMIGIC et al., 2009), modificando as características sensoriais e as propriedades tecnologias da carne.Em contrapartida, a utilização de calor seco, através do uso de chamuscador, elimina os micro-organismos presentes na superfície suína através da aplicação direta e rápida da chama na carcaça, sem acarretar em alterações do músculo (SOFOS \& SMITH, 1998 e JAY, 2005). Ademais, este último é um procedimento aprovado por todas as autoridades sanitárias mundiais, sendo barato, simples e seguro (não forma produtos tóxicos).

Assim, os resultados deste estudo podem servir de suporte para 0 desenvolvimento e implementação de novas estratégias de abate utilizando a aplicação de calor seco de forma complementar em mais uma etapa do abate de suínos, como medida para reduzir os índices de contaminação, aumentando desta forma, a segurança dos produtos ofertados no mercado.

\section{CONCLUSÃO}

Os resultados desta pesquisa evidenciaram que o uso de um segundo chamuscador (calor seco) como última etapa da área "suja" do processo de abate de suínos configurou uma metodologia alternativa eficiente na redução da carga microbiana superficial de carcaças, consistindo em uma adaptação barata, simples e segura à rotina convencional de abate.

\section{REFERÊNCIAS BIBLIOGRÁFICAS}

APHA - American Public Health Association. 2001. Compendium of Methods for the Microbiological Examination of Foods. Washington. DC, 676p.

BESSA, M. C.; COSTA, M.; CARDOSO, M. 2004. Prevalência de Salmonella spp. em suínos abatidos em frigoríficos do Rio Grande do Sul. Pesquisa Veterinária Brasileira, Seropédica,v. 24, n. 2, p. 80-84.

BOSILEVAC, J. M.; NOU, X.; BARKOCYGALLAGHER, G. A.; ARTHUR, T. M.;KOOHMARAIE, M. 2006. Treatments using hot water instead of lactic acid reduce levels of aerobic bacteria and Enterobacteriaceae and reduce the prevalence of Escherichia coli O157:H7 on preevisceration beef carcasses. Journal of Food Protection, Ames, v. 69, n.8, p. 1808-1813.

BRASIL. 1995. Ministério da Agricultura, Pecuária e Abastecimento. Portaria $\mathbf{n}^{\circ}$ 711, de 01 de novembro de 1995. Aprova as normas técnicas de instalações e equipamentos para abate e 
industrialização de suínos. Diário Oficial [da] República Federativa do Brasil, Brasília, DF, 03 de novembro de 1995. Seção I, p. 17625.

BRASIL. 2007. Ministério da Agricultura, Pecuária e Abastecimento. Circular $\mathbf{n}^{\mathbf{0} 130}$, de 13 de fevereiro de 2007. Exportação de carne suína para os Estados Membros da União Europeia.

CARPENTER, C. E.; SMITH, J. V.; BROADBENT, J. R. 2011. Efficacy of washing meat surfaces with $2 \%$ levulinic, acetic, or lactic acid for pathogen decontamination and residual growth inhibition. Meat Science, Oxford, v. 88, n.2, p. 256-260.

CATTANI, C. S. O; FUCHS, P. I. P.; CIROLINI, A.; VIEIRA, C. R. W. 2013. Métodos alternativos para contagem de micro-organismos em carcaças suínas. Ciência Rural, Santa Maria, v. 43, n.6, p. 1031-1036.

COATES, K. J.; BEATTIE, J. C.; MORGAN, I. R.; WIDDERS, P. R. 1995. The contribution of carcass contamination and the boning process to microbial spoilage of aerobically stored pork. Food Microbiology, London, v.12, p. 49-54.

FAUCITANO, L.; IELO, M. C.; STER, C.; LO FIEGO, D. P.; METHOT, S.; SAUCIER, L. 2010. Shelf life of pork from five different quality classes. Meat Science, Oxford, v.84, p. 466-469.

FORSYTHE, S. J. 2002. Microbiologia da segurança alimentar. Porto Alegre: Artmed.

HUFFMAN, R. D. 2002. Current and future technologies for the decontamination of carcasses and fresh meat. Meat Science, Oxford, v. 62, n. 3, p. 285-294.

INTERNATIONAL COMMISSION ON MICROBIOLOGICAL SPECIFICATI ONS FOR FOODS. 2005. Microorganisms in food: Microbial ecology of food commodities. 2. ed. Nova York.
JAY, J. M. 2005. Microbiologia de alimentos. Porto Alegre: Artmed.

KOOHMARAIE, M.;ARTHUR, T. M.; BOSILEVAC, J. M.;GUERINI, M.; SHACKELFORD, S. D.; WHEELER, T. L. 2005. Post-harvest interventions to reduce/eliminate pathogens in beef. Meat Science, Oxford, v. 71, n.1, p. 79-91.

LARA, G. H.;RIBEIRO, M. G.;LEITE, C. Q.; PAES, A. C.;GUAZZELLI, A.; DA SILVA, A. V.;SANTOS, A. C.; LISTONI, F. J. 2011. Occurrence of Mycobacterium spp. and other pathogens in lymph nodes of slaughtered swine and wild boars. Research in Veterinary Science, Midlothian v. 90, p.185-188.

LIMA, E. S.; PINTO, P. S. A.; DOS SANTOS, J. L.; VANETTI, M. C.; BEVILACQUA, P. D.; DE ALMEIDA, L. P.; PINTO, M. S.; DIAS, F. S. 2004. Isolamento de Salmonella sp. e Staphylococcus aureus no processo do abate suíno como subsídio ao sistema de Analise de Perigos e Pontos Críticos de Controle - APPCC. Pesquisa Veterinária Brasileira, Seropédica, v. 24, n. 4, p. 185-190.

MACHADO, A. R.; GOUVEIA, F. C.; PICININ, L. D. A.; KICH, J. D.; CARDOSO, M. R. I.; FERRAZ, S. M. 2013. Avaliação microbiológica e físicoquímica de pernís suínos tratados com ácidos orgânicos e/ou vapor no controle da contaminação superficial por Salmonella typhi-murium. Ciência Animal Brasileira, Goiânia, v.14, n.3, p. 345-351.

PRASAI, R. K.; ACUFF, G. R.; LUCIA, L. M.; MORGAN, J. B.; MAY, S. G.; SAVELL, J. W. 1992. Microbiological Effects of Acid Decontamination of Pork Carcasses at Various Locations in Processing. Meat Science, Oxford,v.32, p. 413-423.

SILVA, M. C; FARIA, G. S.; DE PAULA, D. A. J.; MARTINS, R. P; CARAMORI JUNIOR, J. G.; KICH, J. D.; COLODEL, 
E. M.; NAKAZATO, L.; DUTRA, V. 2009. Prevalência de Salmonella sp. em suínos abatidos no estado de Mato Grosso. Ciência Rural, Santa Maria, v. 39, n. 1, p. 266-268.

SMIGIC, N.; RAJKOVIC, A.; NIELSEN, D. S.; SIEGUMFELDT, H.; UYTTENDAELE, M.; DEVLIEGHERE, F.; ARNEBORG, N. 2009. Intracellular $\mathrm{pH}$ as an indicator of viability and resuscitation of Campylobacter jejuni after decontamination with lactic acid. International Journal of Food Microbiology, Amsterdam, v. 135, n. 2, p. 136-143.

SOFOS J. N.; GEORNARAS I. 2010. Overview of current meat hygiene and safety risks and summary of recent studies on biofilms, and control of Escherichia coli O157:H7 in nonintact, and Listeria monocytogenes in ready-toeat, meat products. Meat Science, Oxford, v. 86, n.1, p. 2-14.

SOFOS, J. N.; SMITH, G. C. 1998. Nonacid meat decontamination technologies: Model studies and commercial applications. International Journal of Food Microbiology, Amsterdam, v.44, p.171-188.

SWANENBURG, M.; VAN DER WOLF, P. J.;URLINGS, H. A.; SNIJDERS, J. M.; VAN KNAPEN, F. 2001. Salmonella in slaughter pigs: the effect of logistic slaughter procedures of pigs on the prevalence of Salmonella in pork. International Journal of Food Microbiology, Amsterdam, v. 70, n.3, p. 231-242.

TORTORA, G. J.; FUNKE, B. R.; CASE, C. L. 2008. Microbiologia de alimentos. 6 ed. Artemed, Porto Alegre. 